\title{
NORMATIVE ISOMETRIC HIP MUSCLE FORCE VALUES ASSESSED BY A MANUAL DYNAMOMETER
}

\section{VALORES NORMATIVOS DA FORÇA ISOMÉTRICA DOS MÚSCULOS DO QUADRIL PELA DINAMOMETRIA MANUAL}

\author{
Glauber Alvarenga ${ }^{1}$, Henry Dan Kiyomoto ${ }^{2}$, Emília Cardoso Martinez ${ }^{3}$, Giancarlo Polesello ${ }^{1,4,5}$, Vera Lúcia dos Santos Alves ${ }^{1,4,5}$ \\ 1. Irmandade da Santa Casa de Misericórdia de São Paulo, Serviço de Fisioterapia, São Paulo, SP, Brazil. \\ 2. Faculdade São Judas Tadeu, São Paulo, SP, Brazil. \\ 3. Faculdades Metropolitanas Unidas, São Paulo, SP, Brazil. \\ 4. Irmandade da Santa Casa de Misericórdia de São Paulo, Faculdade de Ciências Médicas da Santa Casa de São Paulo \\ 5. Universidade de Mogi das Cruzes, Serviço de Fisioterapia da Irmandade da Santa Casa de Misericórdia de São Paulo , São Paulo, SP, Brazil.
}

\section{ABSTRACT}

Objective: Hand-held dynamometry is a quantitative and accessible means of determining the isometric force of muscle groups. Methods: A total of 52 women aged 20-29 years with no complaints of hip pain who were sedentary or sporadically active and had a body mass index of $18.5-24.99 \mathrm{~kg} / \mathrm{m}^{2}$ were included. All participants underwent bilateral assessments using hand-held dynamometry of the flexor, extensor, adductor, and abductor muscles as well as the internal and external rotator hip muscles. All hip movements were measured. All contraction data collected by the dynamometer are expressed in kilograms, normalized according to body weight, and expressed as percentages. Results: The flexor muscles exhibited an isometric muscle force of $38.54 \%$ of body weight versus a muscle force of $27.04 \%$ for the extensor muscles, $16.89 \%$ for the adductors, $16.85 \%$ for the abductors, and $17.09 \%$ for the external rotators, and $23.82 \%$ for the internal rotators. Conclusion: Standardization of isometric strength values according to body weight proved feasible. This result is important for clinical practice since it allows the establishment of patterns of normality and criteria for discharge, return to sports, or assessment of the impact of injuries in terms of loss of muscle strength. Level of evidence: III, Development of diagnostic criteria on consecutive patients (with universally applied reference "gold" standard).

Keywords: Hip. Muscle strength dynamometer. Muscle strength.

\section{RESUMO}

Objetivo: Determinar valores da força dos músculos do quadril em mulheres jovens, normalizados pela porcentagem do peso corporal. Métodos: Incluídas 52 mulheres entre 20 e 29 anos, sem queixas algicas no quadril, consideradas sedentárias ou irregularmente ativas e com IMC entre 18,50 e 24,99 kg/m2. Todas participantes foram submetidas a avaliação bilateral por dinamometria manual para músculos flexores, extensores, adutores, abdutores, rotadores internos e externos do quadril, os valores foram expressos em forma de porcentagem do peso corporal. Resultados: Não foi encontrada diferença estatística na força entre lados dominante e não dominante. Os músculos flexores apresentaram força muscular isométrica correspondente a 38.54\% do peso corporal, ja extensores apresentaram $27.04 \%$. Os adutores com $16.89 \%$ e abdutores com 16,85\% do peso corporal, não apresentando diferença estatística entre eles. Os rotadores externos atingiram 17.09\% do peso corporal e rotadores internos chegaram a 23,82\%. Conclusão: Mostrou-se possível a padronização e obtenção dos valores de força isométrica em relação ao peso corporal. Para prática clínica este resultado é importante por possibilitar conhecimento de padrões de normalidade e utilizar estes dados como critérios de alta, retorno ao esporte e avaliação da repercussão de diversas lesões na perda de força muscular. Nível de evidência III, Estudo de pacientes não consecutivos sem padrão de referência "ouro" aplicado uniformemente.

Descritores: Quadril. Dinamômetro de Força Muscular. Força Muscular.

Citation: Alvarenga G, Kiyomoto HD, Martinez EC, Polesello G, Alves VLS. Normative isometric hip muscle force values assessed by a manual dynamometer. Acta Ortop Bras. [online]. 2019;27(2):124-8. Available from URL: http://www.scielo.br/aob.

\section{INTRODUCTION}

Assessment of muscle force face of parameters of normality can provide criteria for hospital discharge for operated patients or even for the return to sport. Assessing muscle force, however, may not always be straightforward, since numerous techniques exist, each with its own inherent particularities. ${ }^{1}$
A hand-held dynamometer is one of the electronic means of assessing muscle force. ${ }^{1-3}$ The method of quantifying the force of the hip muscles, particularly when the assessment is always performed by the same examiner. When this criterion is not observed, the reproducibility of the method becomes questionable. Factors such as patient positioning and compensation from other muscles further

All authors declare no potential conflict of interest related to this article.

The study was conducted at the Physical Therapy Department of Irmandade da Santa Casa de Misericórdia de São Paulo, SP, Brazil.

Correspondence: Vera Lúcia dos Santos Alves, R. Dr. Cesário Motta Jr, 61, Vila Buarque - São Paulo, SP, Brazil. 01221-020. Email: fisioterapiasc@uol.com.br 
affect the comparability of results. Also, inadequate positioning of the patient or compensation of movements during the test are factors which can hamper inter-examiner comparability. ${ }^{4,5}$

Studies have described methods for dynamometer fixation, reducing the risk of examiner bias, thereby increasing the reliability of this approach for measuring muscle force. ${ }^{6-8}$ However, normative values for many muscle groups are lacking. Furthermore, the majority of studies report results based on linear regression calculations, hampering the clinical application of the data obtained. ${ }^{9-11}$

In order to determine normative values, body weight, age, sex, and physical fitness should be taken into account when analyzing the data obtained, given the large disparity in values found between men and women, young and older adults, or athletes and sedentary individuals. However, the ease and convenience in applying the test justify the need for predictive values for athlete and non-athletes. ${ }^{9-11}$ Therefore, the objective of the present study was to determine values of hip muscle force in young women, with normal percentage of body weight.

\section{MATERIALS AND METHODS}

\section{Main outcome measures}

All hip movements were measured. All contraction data collected by the dynamometer were expressed in kilograms and normalized according to body weight and expressed as percentages.

\section{Design}

This cross-sectional study was conducted by the physiotherapy research team at a tertiary hospital with a public service located in São Paulo city after approval by the Research Ethics Committee under protocol number: 25567913.0.0000.5479.

\section{Setting}

Sampling was performed by agreement, all participants were recruited in the course of physical therapy at a university and evaluated in a physiotherapy research laboratory, where they initially answered an evaluation assessment about their health history and physical activity practice, after responding to the questionnaires the participants were submitted to manual dynamometry with two evaluators.

They were duly informed about the procedures to be performed and signed the Free and Informed Consent Form. Recruitment and data collection was performed between March 2015 and January 2016

\section{Participants}

Participants that met the following criteria were included: aged 20 29 years, To avoid the selection of participants with different body composition, we only included participants with body mass index of between 18.50 and $24.99 \mathrm{~kg} / \mathrm{m}^{2}$, and classified as sedentary or sporadically active according to the International Physical Activity Questionnaire (IPAQ), which determines the type and amount of regular physical exercise practiced by participants. ${ }^{12}$ The IPAQ questionnaire was used for selecting sedentary participants or those with minimal physic activity only, excluding athletes or those with regular physical activity. Therefore, only participants with the same pattern of muscle strength were selected.

Participants were excluded if they had pain or previous injury on the hip or lumbar spine, as were those who had rheumatic, heart, lung, neurological conditions or severe limitations in range of movement, which were reported during the completion of the assessment about the health history, without an additional specific physical examination.

\section{Interventions}

Data where collected on age, weight, height and dominant leg of the participants, who all answered the IPAQ questionnaire ${ }^{13}$ and were subsequently submitted to muscle force testing performed in physiotherapy research laboratory located in São Paulo city. A hand-held dynamometer was used, along with an examination table, a fixation belt and a triple suction cup device. The hand-held dynamometer (MICROFET 2, Draper, USA) was attached to the limb under test using a rigid belt secured to the wall by a suction cup for dynamometer fixation. The movements requested for the assessment were adduction and abduction, flexion and extension, as well as internal and external rotations of the hip. All dynamometry measures collected by the dynamometer were expressed in kilograms. The positioning used for placement of the dynamometer was as described by Thorborg et al. ${ }^{14}$

Patients first performed two low intensity contractions to learn the movements requested during the test. This was followed by five maximal voluntary isometric contractions performed for five seconds each, to evaluate the strength of the muscle groups involved.

Rest intervals of 15 seconds were allowed between contractions to prevent muscle fatigue during the test. The examiner explained the test and then monitored it avoiding compensations. Standardized instructions were given to the participants assessed, requesting that they exert maximum force throughout the test, while another examiner recorded the data obtained. Verbal stimuli were given during the test in order to encourage maximum muscle performance by participants. Three verbal stimuli were standardized for each muscle contraction performed. All the tests were carried out bilaterally, starting with the non-dominant side, and the highest force value of the five contractions attained was recorded. The anatomical landmarks used as a reference for dynamometer placement are listed in Table 1.

Strength values obtained in kilograms from dominant and non-dominant sides for the muscles tested in all participants were converted to values proportional to individual body weight.

To estimate the mean muscle strength in women aged 20 to 29 , the sample size was calculated. The data was generated from the first 10 individuals collected during the pilot study and used some statistical assumptions. It was assumed that the data distribution would be symmetric (Normal), a 95\% confidence interval (then $Z=1.96$ ) and with a margin of error of 3 units. The standard deviation of muscle strength in the population is unknown, but through the first 10 individuals tested in this study it was estimated that the standard deviation of hip muscle strength ranged from 4 to 10 units. To estimate the sample size, considered the highest standard deviation to obtain the most conservative sample size, requiring 45 patients for the study, and considering possible deletions of up to $15 \%$ throughout the study, we recruited 52 subjects.

Data analysis was performed using version 22.0 of the SPSS software for Macintosh computers. Values obtained for normal distribution

\begin{tabular}{l}
\begin{tabular}{l} 
Table 1. Anatomical landmarks for the dyanamometer placement for hip \\
strength measurement. \\
\hline Movement
\end{tabular} \\
\begin{tabular}{c|c} 
Dlexion in sitting position & $5 \mathrm{~cm}$ above the upper border of the patella \\
\hline Extension in prone position & $\begin{array}{c}5 \mathrm{~cm} \text { above the medial malleolus, } \\
\text { at the triceps surae }\end{array}$ \\
\hline Abduction in supine position & $\begin{array}{c}5 \mathrm{~cm} \text { above the proximal border } \\
\text { of the lateral malleolus }\end{array}$ \\
\hline Adduction in supine position & $\begin{array}{c}5 \mathrm{~cm} \text { above the proximal border } \\
\text { of the medial malleolus }\end{array}$ \\
\hline Medial rotation in sitting position & $\begin{array}{c}5 \mathrm{~cm} \text { above the proximal border } \\
\text { of the lateral malleolus }\end{array}$ \\
\hline Lateral rotation in sitting position & $5 \mathrm{~cm}$ above the proximal border \\
of the medial malleolus
\end{tabular} \\
\hline
\end{tabular}


muscle groups were submitted to Kolmogorov-Smirnov test and for comparison between the left and right sides we used the t-student tests for paired samples and the Wilcoxon test Signed Rank Test. (Figure 1) A $p$-value lower than $5 \%$ ( $p \leq 0.05)$ was considered statistically significant.

\section{RESULTS}

A total of 52 participants were evaluated in this study with bilateral analysis of the hip strength, with a total of 104 hips analyzed, as depicted in Figure 2. Demographic and anthropometric data of the participants are shown in Table 2.

Mean peak isometric torque, along with confidence interval, standard deviation and p-values are shown in Table 3, confirming the absence of statistically significant difference between dominant and non-dominant sides. Given the absence of statistical difference between the values for dominant and non-dominant sides, these values were pooled together to yield normative values, independently of the side evaluated. Reference values for the muscle groups

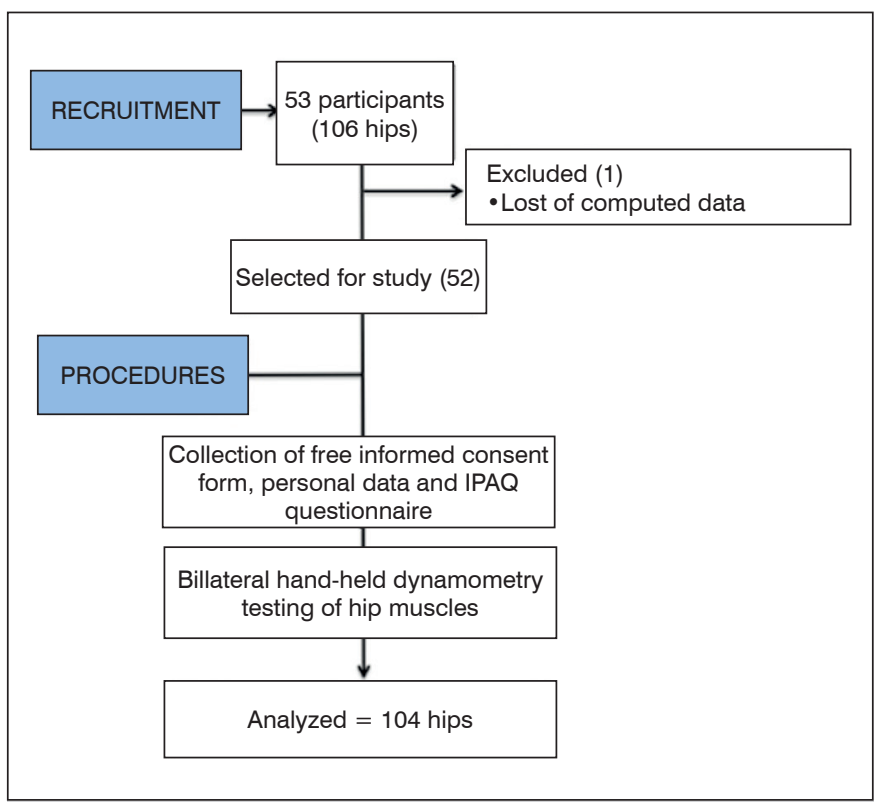

Figure 1. CONSORT diagram showing the flow of patient participants through the trial.

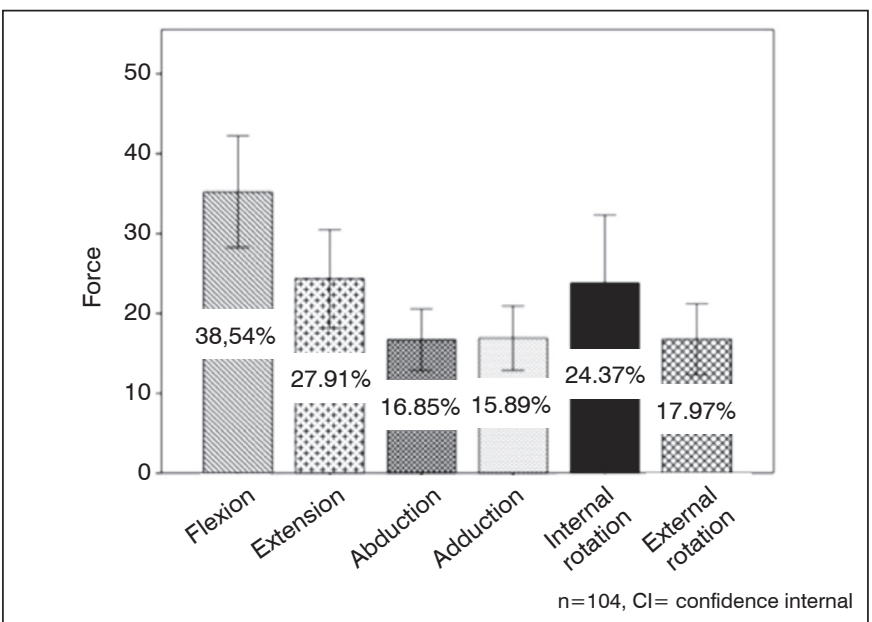

Figure 2. Mean force attained for all hip movements of the 104 joints included in the study, in relation to body weight.
Table 2. Characteristics of participants according to age, weight, height and body mass index (BMI).

\begin{tabular}{c|c|c|c|c}
\hline & Age (years) & Weight $(\mathbf{k g})$ & Height $(\mathbf{c m})$ & BMl $\left(\mathbf{k g} / \mathbf{m}^{2}\right)$ \\
\hline $\mathrm{n}=52$ & 22.17 & 58.40 & 1.62 & 22.25 \\
\hline $\mathrm{SD}$ & 2.08 & 6.49 & 5.57 & 1.97 \\
\hline
\end{tabular}

$\mathrm{SD}=$ standard deviation.

studied, together with confidence interval, standard deviation and p-values, are given in Table 4.

The flexor muscles exhibited the highest peak isometric torque, followed by the extensors and internal rotators. The adductor, abductor and external rotator muscles had similar values, as depicted in Figure 2.

Based on the values obtained, the agonist/antagonist relationship can be determined, where flexors were found to be stronger than extensors $(p<0.01)$, the internal rotators stronger than external rotators $(p<0.01)$ while abductors did not differ significantly to adductors $(p=0.96)$ (Figure 3$)$.

\section{DISCUSSION}

The determination of normative values for hip muscle force using hand-held dynamometry can yield reference data for the assessment, treatment and discharge criteria of patients with lower limb injuries. ${ }^{11,13,14}$ This study explored a practical and reproducible method of normalizing testing to facilitate clinical practice.

Numerous studies reporting linear regression calculations, and even normalizing values for body weight, have been published for some hip muscle groups. However, studies in the literature assessing the force of all the groups are scarce, especially those normalizing values based on body weight. $9,11,15,16$

In the present study, all the muscle groups of the hip were assessed and their absolute values expressed based on percentage of body weight, facilitating the clinical use of dynamometry. Using this approach, professionals could assess loss of muscle strength, normalizing values obtained without the need for complex equations such as regression calculations and those adopted in other studies, 8,11 in which values are expressed in absolute form, precluding their use as normative values.

The greater reliability conferred by using a fixation belt during handheld dynamometry compared with resistance offered by the examiner was reported in 1991. Values reported by studies using hand resistance are often called into question owing to the numerous factors influencing the reliability of data collection. In addition, the values obtained using a dynamometer with belt-fixation are higher than those measure by hand resistance, highlighting the inability of examiners to collect maximum isometric force without the aid of external resources. ${ }^{6,8,16}$ Therefore, the results of the present study cannot be compared against values of studies which have not employed external belt-fixation. In the literature review, only one study was found that assessed all movements of the hip with the same placement parameters as the present study. ${ }^{13}$ These assessments however, were performed without the use of fixation belts and data were expressed as absolute values. This was the case because the primary aim of the study in question was normatization of the positions of the tests, and not to determine the normative value of muscle forces. ${ }^{13}$

The assessment protocol applied in the present study used the highest of five contractions of each muscle group as a reference. This form of analysis was chosen, as opposed to calculating the average value of contractions, in order to make the assessment faster and more clinically reliable. Indeed, the literature has shown no statistical difference between using the highest value obtained among contractions and the mean of muscle contractions. ${ }^{13}$ 
Table 3. Mean force of hip muscles for flexors, extensors, adductors, abductors, internal and external rotators in relation to body weight of the 52 participants in the study.

\begin{tabular}{c|c|c|c|c|c|c|c}
\hline Muscle group & Dominant side & $95 \% \mathbf{C l}$ & Standard deviation & Non-Dominant side & $95 \% \mathbf{C l}$ & Standard deviation & $\mathbf{P}$ \\
\hline Flexors & $38.44 \%$ & $36.35-40.52 \%$ & $7.50 \%$ & $38.64 \% \%$ & $36.47-40,81 \%$ & $7.79 \%$ & 0.768 \\
\hline Extensors & $27.91 \%$ & $26.08-29.75 \%$ & $6.60 \%$ & $26.17 \%$ & $24.43-27.91 \%$ & $6.25 \% \%$ & 0.004 \\
\hline Abductors & $17.22 \%$ & $15.95-18.49 \%$ & $4.56 \%$ & $16.47 \%$ & $15.43-17.52 \%$ & $3.75 \%$ & 0.172 \\
\hline Adductors & $17.33 \%$ & $16.10-18.56 \%$ & $4.42 \%$ & $16.45 \%$ & $15.44-17.47 \%$ & $3.63 \%$ & 0.015 \\
\hline Internal rotators & $24.37 \%$ & $21.97-26.77 \%$ & $8.61 \%$ & $23.28 \%$ & $20.94-25.62 \%$ & $8.40 \%$ & 0.121 \\
\hline External rotators & $17.97 \%$ & $16.44-19.50 \%$ & $5.50 \%$ & $16.21 \%$ & $14.99-17.43 \%$ & $4.38 \%$ & 0.003 \\
\hline
\end{tabular}

$\mathrm{n}=52 ; \mathrm{Cl}=$ confidence interval.

\begin{tabular}{|c|c|c|c|}
\hline Muscle group & Normative value & $95 \% \mathrm{Cl}$ & Deviation \\
\hline Flexors & $38.54 \%$ & $37.06-40.02 \%$ & $7.61 \%$ \\
\hline Extensors & $27.04 \%$ & $25.79-28.30 \%$ & $6.46 \%$ \\
\hline Abductors & $16.85 \%$ & $16.03-17.66 \%$ & $4.17 \%$ \\
\hline Adductors & $16.89 \%$ & $16.11-17.68 \%$ & $4.05 \%$ \\
\hline Internal rotators & $23.82 \%$ & $22.18-25.47 \%$ & $8.48 \%$ \\
\hline External rotators & $17.09 \%$ & $16.12 \%-18.07 \%$ & $5.03 \%$ \\
\hline
\end{tabular}

$\mathrm{n}=104, \mathrm{Cl}=$ confidence interval.

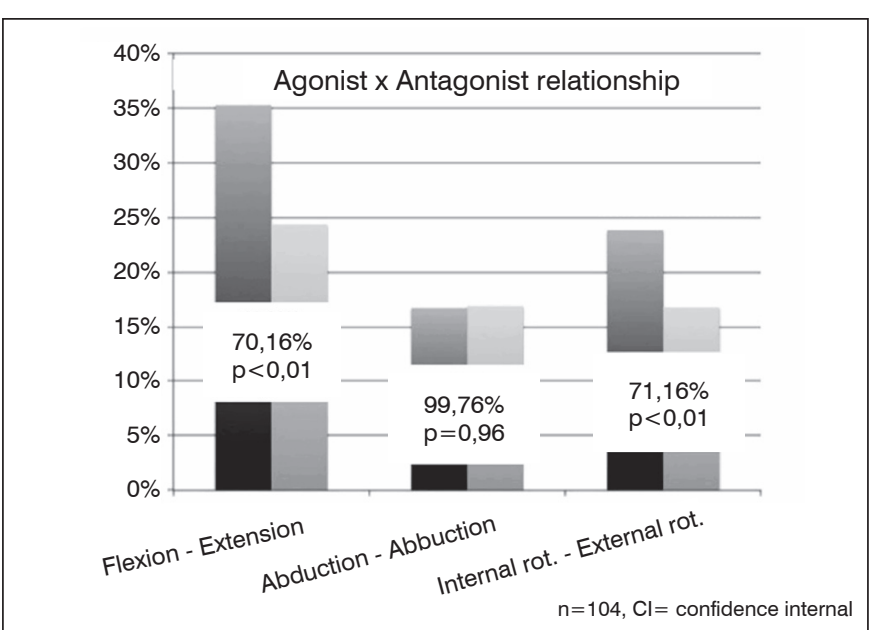

Figure 3. Values of muscle difference found between agonists and antagonists for the 104 hip joints included in the study.

The inclusion of women aged 20-29 years having BMI within normal limits was to establish the normative values for this specific population, given the large variation in data found according to age and sex in previous studies..$^{11,16}$

Since the literature suggests that muscle strength declines with age, this study centered on assessing young women, serving as initial reference values for comparisons with older age groups..$^{10}$ Another factor influencing the choice of age group was the lower incidence of hip injuries in younger adults, facilitating data collection in individuals with healthy hips. Women whose body mass index lay within normal values were recruited due to the large variation in peak torques which can occur in women who are under or overweight, a factor which could lead to bias in the equation converting absolute values to percentage of body weight.

In the studies of van der Ploeg et al., ${ }^{11}$ Andrews et al., ${ }^{9}$ and Bohannon, ${ }^{16}$ normative values of maximum voluntary isometric muscle contraction were obtained for a range of muscle groups, including hip muscles. These studies however, only included flexor and abductor muscles. The present study focused on assessing the muscle groups involved in flexion, extension, abduction, abduction, internal rotation and external rotation of the hip, thereby establishing reference strength values of these muscles and determining the relationship between agonists and antagonists.

The values obtained for hip flexion were significantly higher than data reported by Andrews et al. ${ }^{9}$ We believe this disparity can be explained by the difference in age group of the populations studied of 50-79 years in the cited study versus 20-29 years in the present investigation. Previous studies have also cited a decline in muscle strength with advancing age..$^{10}$

No normative values are available for hip extensors, hampering comparisons of the present study results. In the study by Thorborg et al. ${ }^{14}$ the aim of the study was not to determine a predictive value, and yet marked differences can be seen between the force of flexor and extensor muscles, with extensors having lower peak isometric torque, akin to results found in the present study.

The values obtained in the evaluation of abductors were significantly lower than those found by Andrews et al., ${ }^{9}$ and Bohannon. ${ }^{16}$ The main factor to be considered to justify this difference is placement of the dynamometer which, in both studies, was positioned laterally to the femoral condyles. By contrast, the distal position was used in the present study, where the literature suggests greater reliability can be attained with this latter placement. ${ }^{17}$ The fact that no external fixation belt was used may have contributed to the difference in values, although this hypothesis was not explored in the present study. The force values of hip abductors were very similar to those obtained in adductors, contrasting with results found in previous studies using isokinetic dynamometry. ${ }^{18}$ However, the muscle contractions used in the cited assessment had different characteristics according to position to those performed in the present study.

Studies which employed the same protocol for positioning participants and dynamometer showed no statistical difference in force between hip adductor and abductor muscles. The values reported cannot be compared between the studies since the data were expressed in absolute values as opposed to percentage of body weight in the present study. 8,14

The values found in the present study for mean peak torque of internal rotators were greater than for external rotators, whereas the study of Thorborg et al., ${ }^{19}$ reported higher values for external than internal rotators with the hips placed in a neutral position.

The proposed explanation for this difference may be the positions of the participants, who were placed in a prone position with neutral hip position and knees flexed at 90 degrees. By contrast, in the present study participants were placed in a sitting position on the table with knees and hips flexed at 90 degrees. In another study conducted by Thorborg et al. ${ }^{14}$ in which hips were assessed in the same position as the present study, higher values of peak isometric torque were obtained for internal rotators than external rotators, mirroring the results of the present study.

In order to reproduce muscle force tests using hand-held dynamometry, placement of the dynamometer must be carried out carefully. Another limitation of the study is the collection of values only for women between 20 and 29 years with normal BMI, precluding their 
use in groups with different gender, body weight and age bracket to those studied. This study should prompt further analysis of other groups with different demographic profiles to those investigated, given that the potential of dynamometry normalized by body weight as an additional resource in clinical practice has been shown.

\section{CONCLUSION}

The standardization of isometric strength values in relation to body weight has proven to be feasible, but there is a need of more studies done with people with different ages and genres. The values obtained in this study can be applied as standard only for people with the same profile.

The result is important for clinical practice, allowing patterns of normality to be established and used as criteria for discharge, return to sport or assessment of the impact of different injuries in terms of loss of muscle strength.

\section{FUNDING}

This research did not receive any specific grant from funding agencies in the public, commercial, or not-for-profit sectors.

AUTHORS' CONTRIBUTIONS: Each individual author contributed individually and significantly to the development of this work. GA (0000-0003-23232966)*: Conception and design / Data Collection; HDK (0000-0003-0528-8923)*: Statistical analysis. ECM (0000-0002-0377-4058)*: Writing the article; GP (0000-0002-9524-8871)*: Conception and design; VLSA (0000-0002-9623-8704)*: Conception and design. All authors read and approved the final manuscript. *ORCID (Open Researcher and Contributor ID).

\section{REFERENCES}

1. Guimarães R, Pereira JS, Batista LA, Scianni CA. Dinamômetro Manual Adaptado: Medição de Força Muscular do Membro Inferior. Fit Perform. 2005;4(3):145-9.

2. Lamontagne A, Malouin F, Richards CL, Dumar F. Evaluation of reflex- and nonreflex-induced muscle resistance to stretch in adults with spinal cord injury using hand-held and isokinetic dynamometry. Phys Ther. 1998;78(9):964-75.

3. Teixeira-Salmela L, Augusto A, Silva PC, Lima RMC, Goulart F. Musculação e condicionamento aeróbio em hemiplégicos: impacto no desempenho motor. Braz J Phys Ther. 2003;7(3):209-15.

4. Bohannon RW. Hand-held dynamometry: factors influencing reliability and validity. Clin Rehabil. 1997;11(3):263-4.

5. Edwards RH, McDonnell M. Hand-held dynamometer for evaluating voluntary-muscle function. Lancet. 1974;2(7883):757-8.

6. Kramer JF, Vaz MD, Vandervoort AA. Reliability of isometric hip abductor torques during examiner- and belt-resisted tests. J Gerontol. 1991;46(2):M47-51.

7. Taylor NF, Dodd KJ, Graham HK. Test-retest reliability of hand-held dynamometric strength testing in young people with cerebral palsy. Arch Phys Med Rehabil. 2004;85(1):77-80

8. Thorborg K, Bandholm T, Hölmich P. Hip- and knee-strength assessments using a hand-held dynamometer with external belt-fixation are inter-tester reliable. Knee Surg Sports Traumatol Arthrosc. 2013;21(3):550-5.

9. Andrews AW, Thomas MW, Bohannon RW. Normative values for isometric muscle force measurements obtained with hand-held dynamometers. Phys Ther. 1996;76(3):248-59.

10. Ramskov D, Pedersen MB, Kastrup K, Lønbro S, Jacobsen JS, Thorborg K, et al. Normative values of eccentric hip abduction strength in novice runners: an equation adjusting for age and gender. Int J Sports Phys Ther. 2014;9(1):68-75.
11. Van der Ploeg RJ, Fidler V, Oosterhuis HJ. Hand-held myometry: reference values. J Neurol Neurosurg Psychiatry. 1991;54(3):244-7.

12. Bohannon RW. Test-retest reliability of hand-held dynamometry during a single session of strength assessment. Phys Ther. 1986;66(2):206-9.

13. Pardini R, Matsudo S, Araújo T, Matsudo V, Andrade E, Braggion G, et al. Validação do questionário internacional de nível de atividade física (IPAQ-versão 6): estudo piloto em adultos jovens brasileiros. Rev Bras Ciênc Mov. 2001;9(3):45-51.

14. Thorborg K, Petersen J, Magnusson SP, Hölmich P. Clinical assessment of hip strength using a hand-held dynamometer is reliable. Scand J Med Sci Sports. 2010;20(3):493-501.

15. Douma RK, Soer R, Krijnen WP, Reneman M, van der Schans CP. Reference values for isometric muscle force among workers for the Netherlands: a comparison of reference values. BMC Sports Sci Med Rehabil. 2014;6(1):10.

16. Bohannon RW. Reference values for extremity muscle strength obtained by hand-held dynamometry from adults aged 20 to 79 years. Arch Phys Med Rehabil. 1997;78(1):26-32.

17. Krause DA, Schlagel SJ, Stember BM, Zoetewey JE, Hollman JH. Influence of lever arm and stabilization on measures of hip abduction and adduction torque obtained by hand-held dynamometry. Arch Phys Med Rehabil. 2007;88(1):37-42.

18. Sugimoto D, Mattacola CG, Mullineaux DR, Palmer TG, Hewett TE. Comparison of isokinetic hip abduction and adduction peak torques and ratio between sexes. Clin J Sport Med. 2014;24(5):422-8.

19. Thorborg K, Bandholm T, Schick M, Jensen J, Hölmich P. Hip strength assessment using handheld dynamometry is subject to intertester bias when testers are of different sex and strength. Scand J Med Sci Sport. 2013;23(4):487-93. 